\title{
Europa y América Latina en la crisis mundial
}

"Dead ends force one to look again and
to retrace one's steps". Y. BLUMEFELD.

Una profunda crisis ha sacudido Ia economía mundial desde principios de la década de los años '70; aún las recientes mejorías en la situación de algunos países -vistas demasiado entusiastamente por algunas personas como la luz al final de un túnel- acentúan la extensión de la crisis y las desigualdades estructurales básicas que caracterizan la economía mundial. Ya que la economía mundial no está experimentando meramente una baja de carácter cíclico, lograr que alcance una expansión estable y competitiva de sus diversas partes exigirá que se lleve a cabo una reestructuración completa del proceso de acumulación de capitales y redistribución de los roles relativos que cada parte deberá desempeñar en el nuevo orden socio-económico.

Una crisis como la actual no tiene una única causa, por lo que uno no debiera sorprenderse al oír interminables discusiones con respecto a la importancia y al carácter especial de las diversas causas y sobre las respectivas medidas de solución que se le plantean. La intervención de las autoridades de gobierno, así como la de organismos internacionales, tienen el propósito de anular o poner un límite a los efectos negativos de estas causas y de modificar indirectamente los marcos de referencia y los parámetros dentro de los cuales operan los agentes económicos privados, incluyendo las compañías multinacionales. Esto plantea la difícil tarea de coordinar políticas internas, aunque este problema no sería tan difícil de tratar si la creciente interdependencia fuera menos desigual de lo que admiten todos aquellos que la utilizan para poner énfasis en la mutualidad de Ios intereses que predominan en la economía mundial, y con el fin de minimizar la necesidad de efectuar cambios estructurales, tanto a niveles internacionales como subnacionales.

Este trabajo está dividido en cuatro partes que tratan las causas de la crisis, sus efectos en Europa y América Latina, y, finalmente, cómo ésta ha afectado las relaciones entre Europa y América Latina.

* En las notas se han dejado las citas en su idioma original. 
1.0. La primera causa de la actual crisis mundial que será analizada es aquella que se relaciona con el hecho que la teoría del modelo socio-económico que se podría describir como el modo de crecimiento "más-de-lo-mismo" ya no se puede aplicarí modelo que se mantuvo viable hasta que fue utilizado dentro de un área limitada del sistema económico mundial. Las tensiones generadas por su adopción por parte de un número de países cada vez mayor, se sintieron en la forma de una inflación generalizada que hizo explosión en la década de los años '70 y que continúa latente, a pesar de que la drástica recesión impuesta sobre la economía mundial la ha detenido un poco. En otras palabras, las expectativas de consumo público y privado han tendido a aumentar en forma más rápida que las posibilidades de producción, que están constreñidas por el simple hecho de que muchos recursos naturales no son renovables y se agotan. A pesar de que el progreso tecnológico ha extendido continuamente los límites de su disponibilidad, estos límites, en realidad existen y el extenderlos aún más, así como la búsqueda de fuentes alternativas, exige enormes y continuas inversiones que, a su vez, se ven comprimidas por la creciente demanda por consumo y la decreciente utilidad ${ }^{2}$.

La crisis del estado benefactor ${ }^{3}$, o mejor, su extensión fuera del mundo desarrollado, ha puesto en tela de juicio la teoría Keynesiana en la que se basó, ya que resulta cada rez más claro que el estado no puede satisfacer la demanda agregada en forma indefinida sin poner en peligro la estabilidad económica y monetaria. Simultáneamente, la capacidad del estado para satisfacerla se ha visto fuertemente afectada por la creciente influencia que tienen los grupos internos, que a menudo se afanan exigiendo demandas incompatibles y están guiados por perspectivas a corto plazo. Las políticas de "participación" sometidas a continuos cambios impidieron

${ }^{1}$ S. Sideri: "Dimensioni Internazionali del Proceso di Sviluppo ed Eroluzione dell'Economia Mondiale", Economia banca e Congiuntura, 4, 3, 1982; y F. Frobel: "The Current Development of the World Economy: Reproduction of Labour and Accumulation of Capital on a World Scale", Review, V. 4, primavera 1982, 529-31 y 542-44. Frobel destaca correctamente que "unlike the organized working class, capital could in principle discard this model should changed circunstances require it"', (p. 531).

2*... profitability in manufacturing remains at a low level, particularly in a number of industrial countries", puntualizó el Director Ejecutivo del FMI, J. de Larosiere, en su discurso al American Interprise Institut, Washington D. C., en diciembre de 1983; Finance and Development, 21, 1, marzo de 1984, 31.

${ }^{3}$ Ver C. Offe (editado por J. Keane): Contradictions of the Welfare state (Londres: Hutchinson, 1984) principaImente capitulos 6 y 8; P. Barcellona: Oltre lo Stato Sociales Economia e politica nella crisi dello Stato Keynesiano (Bari: De Donato, 1980) capitulos 8 y 9; S. Brittan: The Role and Limits of Govemment Crisis (Londres: Temple Smith, 1983); OCDE: The Welfare State in Crisis (Parfs: OCDE, I981) y, por supuesto, J. O'Connor: The Financial Crisis of the State (New York: St. Martin's Press, 1973). 
que se adoptaran planes de acción estables y seguros, de modo que se redujeron las bases de cooperación entre países desarrollados (PD) y más aún entre PD y países en desarrollo (PED), como lo demuestran la "crisis del desarrollo" y la "crisis de ayuda extranjera", que han sido analizadas extensamente en la literatura de los años setenta.

1.I. La creciente interdependencia ha acrecentado la transmisión de estímulos socio-económico-culturales a través de las fronteras; en el contexto de los PD y los PED, sin embargo, han dominado Ios efectos negativos, de manera que las reiteradas declaraciones en el sentido de que la recuperación del Norte es un requisito previo para aquella del hemisferio Sur requiere de una calificación. De hecho, la actual recuperación de la economía estadounidense está teniendo algunos efectos positivos, especialmente en los PD; para los PED, el impacto más visible es aquel de las alzas en las tasas de interés. A pesar que la interdependencia 'leapt out of the textbooks and... arrived on ministers desks everywhere'4, ésta sigue estando 'desbalanceada's. Aun cuando el concepto ha sido puesto en tela de juicio, se le ha colocado el énfasis en que a pesar del aumento de las medidas proteccionistas, la economía mundial se ha mantenido integrada en alto grado, $y$, de hecho, en un aspecto por lo menos, esta misma turbulencia ha dado lugar a aún mayor integración. Esto se aprecia en un rápido aumento de los préstamos internacionales y los mercados de capitales durante la década de los años $70^{6}$.

La estrecha interdependencia de la economía mundial es usada continuamente para:

i) Sostener que la recuperación económica de los PD es crucial para la solución de problemas internacionales y que el desarrollo de los PED depende de esa recuperación; Iuego, para enfatizar esto último, ii) Para sugerir que la actual crisis es esencialmente de de carácter cíclico y que, consecuentemente, no se necesita efectuar ninguna reforma estructural básica interna ni en las relaciones internacionales ni en las nacionales; por último, iii) Para minimizar, por no decir ignorar, la 'posible contribución que podría fortalecer sustancialmente de economías de los PED con su consecuente

${ }^{\star}$ Sylvia Ostry nos recuerda cómo se expresó el entonces Primer Ministro de Nueva Zelandia, R. Muldoon, durante una reunión ministerial de la OCDE efectuada en la primavera de 1983: "The World Economy in 1983: Marking Time", Foreign Affairs, 62, 3, 1984, 533-34. Ella también destaca la sensación intensificada de riesgo y la inseguridad que la interdependencia básicamente transmitió en 1983 y en el momento actual.

oCDE: World Economic Interdependence and the Evolving of North-South Relationship (Parfs, OCDE, 1983), 9.

"Miembros del Consejo Editorial: "The Reality of Economic Interdependence", Finance and Development, 2I, I, marzo de 1984. 
aumento de poder comprador, a los actuales problemas económicos de $\operatorname{los} \mathrm{PD}^{7}$.

La reducción de la soberanía económica interna que la interdependencia conlleva por definición ${ }^{8}$, ha ayudado a limitar el rol del estado y a hacer más difíciles de predecir los efectos que tendrán las políticas internas. Tomando en consideración las tradicionales debilidades de la mayoría de los PED, los peligros que plantea la creciente interdependencia no deben ser pasados por alto. Cálculos hechos por el FMI demuestran que una baja de un uno por ciento anual de la tasa de crecimiento del PNB hasta 1987 de los países desarrollados, aumentaría el déficit de la cuenta corriente de los PED que no son exportadores de petróleo, de los $\$ 60$ mil millones actualmente presupuestados, a $\$ 80$ mil millones. Sin embargo, hay un aspecto levemente desconcertante en la interdependencia: si los PED fueren afectados por una recesión, crecería la presión hacia el proteccionismo y las exportaciones de los PED tenderían a disminuir; si, por otra parte, los PD gozaran de una rápida recuperación económica, las tasas de interés se elevarían y el servicio de la deuda por parte de los PED se haría cada vez más pesado. No obstante, los PED no son los únicos que a menudo se encuentran sufriendo la rápida transmisión de inestabilidad y desbarajuste causada por los fenómenos económicos originados en otras partes y sobre los cuales tienen poco o ningún control. El mejor ejemplo de esta transmisión unidireccional inmediata es aquel de las variaciones de las tatas de intercambio. Más aún, el largo y doloroso proceso de ajuste a tales influencias puede ser anulado en cualquier momento por una ola de cambios originados en el exterior. En todo caso, es sólo en tiempos de crisis... que a menudo se hacen patente las exigencias incompatibles que plantean los objetivos nacionales y colectivos's.

Que esta interdependencia también tiene sus lados positivos queda demostrada por la exitosa batalla contra la inflación que nació de las medidas sincronizadas llevadas a cabo por la OGDE después del segundo impacto producido por el petróleo, medidas que causaron, sin embargo, una severa y larga recesión.

1.2. El serio intento por parte de EE, UU. para poner fin al sis-

${ }^{7}$ A. J. Yeats: Trade and Development Policies (London: Macmillan, 1981), 7.

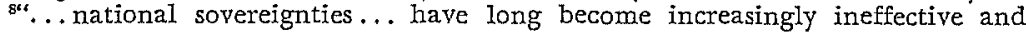
deceptive even for the most powerful countries, or so-called 'superpowers', at home as well as abroad"; $\mathrm{R}$. Triffin, "Concluding Remarks", Banca Nazionale del Lavoro Quarterly Review, 138, septiembre de 1981, 365.

"J. Cable: "Interdependence: a drug or addiction?", International Affairs, 59, 3 , verano de 1983,373 . Esta es una breve pero brillante explicación del significado que tiene la "interdependencia" sobre la base de un análisis de la dependencia de Gran Bretaña en Estados Unidos. Este diplomático británico de alto rango enfatiza al principio de su ensayo que "dependencia e independencia son conceptos más útiles" que interdependencia ( $\mathrm{p} .365)$. 
tema mundial multipolar que había surgido en la década de los años 60 y para reinstaurar su superioridad económica y militar, ha dado origen a un creciente déficit en el financiamiento del rearme de ese gobierno, así como a tasas de interés cada vez más altas que frenan las inversiones productivas, y al aumento del influjo de capitales a EE. UU. Si estas entradas ayudan a financiar algunas nuevas inversiones en EE. UU. ${ }^{10}$, ellas reducen las posibilidades de recuperación de los países donde se gestaron, lo que deja de manifiesto el carácter unidireccional de la interdependencia ${ }^{11}$.

La valorización del dólar es otro aspecto de la economía más robusta de EE. Uu. que, aunque a expensas de los mercados de manufacturas estadounidenses en el exterior, también ayuda a mantener la inflación de EE. Uu., a un nivel bajo. Sin embargo, ya que una gran proporción del comercio mundial y un gran número de productos tiene precio en dólares, un aumento en el valor del dólar hace que su costo relativo aumente para los importadores, dando origen a una presión inflacionaria que es transmitida a la economía mundial12. Los países, entonces, se enfrentan a la alternativa, expresada por el Banco de Inglaterra, de aceptar ellos mismos tasas altas de interés con sus consecuencias dañinas para el crecimiento económico, o reducir sus tasas de intercambio, con los consiguientes efectos dañinos en Ia inflación. Afortunadamente para los PD, los precios de la mayor parte de los productos de primaria importancia, incluyendo el petróleo, han continuado bajando $y$, por lo tanto, Iimitando el daño que producen las medidas estadounidenses en los países industriales.

Las reducciones de impuestos internos en EE. uU. (vale decir, déficit fiscal) fomentan una aguda recuperación en gran parte a expensas de los PED y Europa. De este modo, otras naciones ayudan

${ }^{10} \mathrm{La}$ "... recovery of business fixed. investment ... is central to a substantial expansion". declaró J. de Larosiere en diciembre de 1983 (op. cit.).

11"Such high rates are evidently a major impediment to revival in other countries"; Ostry: "The World Economy", 539. Ella prosigue, "yet the us economy, so far, appears to be less interest-sensitive than other economies, perhaps for tax-rejated reasons, or because of the far greater importance of equity markets than in most other countries, the improved profit flow emanating from the recovery and modest wage behavior. There may be more elusive reasons underlying bullishness, confidence, flexibility, dynamism which are impossible to quantify but undoubtedly important. The Macroeconomic consequences of a growing defense sector, likely rather interestinsensitive, may be still another factor"; Ibid., 539-40.

${ }^{12 "}$ "The effects of dollar appreciation are also a reduction in us inflation and an increase in inflation in Europe. For the us, this 'disinflation' effect is estimated to amount to $1,5 \%$ per year over the 1980-83 period. Finally, the effects are not limited to the us and Europe. IDCs are largely dollar debtors and exporters of primary commodities the real prices of which decline when the doIlar appreciates"; O. Blanchard y R. Dornbusch: "U.s. Deficits, the Dollar and Europe", Banca Nazionale del Lavoro Quarterly Review, 148, marzo de 1984, 106. 
a financiar el proceso de rearme de EE. UU. por medio de su déficit de balanza comercial y entrada de capital13; los otros que contribuyen son los norteamericanos de escasos recursos. La remoción de un $30 \%$ de impuestos retenidos sobre el ingreso percibido por concepto de intereses y dividendos por parte de los inversionistas extranjeros en EE. UU. y que se aplicaría a partir del verano de 1984, se espera que capte entre 15 y $30 \mathrm{mil}$ millones de dólares provenientes del extranjero durante 1984. Este dinero, al ser invertido en bonos de la Tesorería de EE. Uu., fortalecerá al dólar con relación a las demás monedas, lo que hará que el servicio de la deuda extranjera se haga aún más difícil, ya que los deudores enfrentarán una presión hacia el alza que afectará las tasas de interés percibidas en los mercados de capitales para compensar la fuga de dinero a EE. UU. Y la presión hacia la baja en los precios de los productos.

Es solamente la posición que ocupa dentro del sistema mundial y su renovado poder, lo que permite a EE. UU., y solamente a EE. UU, continuar aplicando efectivamente una política fiscal expansionista Keynesiana -el consumo privado y la construcción residencial han sido las causales más importantes de su reciente recuperación ${ }^{14}$ con una postura monetaria restrictiva, aunque la viabilidad a largo plazo de este enfoque merece dudas, especialmente si la inversión industrial y el sector exportador no reviven. La información concerniente al segundo trimestre de 1984 muestra que la inversión empresarial, en relación con el PNB, fue ligeramente menor que el $11,7 \%$ alcanzado cuatro años antes.

1.3. Como aspecto relevante de la intención por parte de EE. UU. de restablecer su preeminencia que había sido erosionada por la supuesta pérdida de, incluso, la paridad militar con el bloque oriental, la détente debía ser reemplazado por el enfrentamiento. Las tensiones intraeuropeas resultantes han generado más pérdidas económicas para Europa Occidental al coartar su acceso a los mercados orientales $y$, de ese modo, hacer más difícil su recuperación. Además, la actitud de enfrentamiento de EE.UU. ha dividido a Europa Occidental y ha introducido mayores incertidumbres en sus cálculos económicos, reduciendo así su capacidad de actuar en forma coordinada y coherente. La raíz de la actual 'crisis de Europa'

${ }^{23}$ Según la declaración de P. Volker el 25 de julio de 1984, el flujo de capital de $\$ 80-90$ mil millones de este año representa un cuarto del ahorro neto de Estados Unidos, y por lo tanto, "we are directly or indirectly financing our budget deficit abroad", declara The Economist, 28 de julio, 1984, 29.

${ }^{14} \mathrm{La}$ fuerza de la recuperación está en la reducción de impuestos de 1981, que se espera generará una reducción de $\$ 300$ mil millones en impuestos personales y $\$ 50$ mil millones en impuestos empresariales durante el periodo 198385. Se estima que los beneficios por impuestos han más que compensado el costo del alza de las tasas de interés por inversión empresarial. 
está en esta decisión unilateral por parte de EE. UU. de modificar su polftica con respecto al bloque oriental.

1.4. Otra importante causal de la crisis es la naturaleza y dirección del progreso tecnológico fuertemente influenciado por la estructura y la evolución del sistema socio-económico estadounidense. Para nosotros, el impacto del progreso tecnológico en los PD ha contribuido en los siguientes aspectos:

i) El bien conocido fenómeno de la baja de empleos en el sector manufacturero, tendencia que ha contribuido en forma importante a la redistribución del ingreso después de la Segunda Guerra Mundial en favor de los trabajadores en general y el trabajador no especializado, en particular. Esta redistribución ha favorecido el rápido aumento del ahorro en términos laborales antes que la expansión en términos de capacidad, disminuyendo al mismo tiempo la propensión al ahorro.

ii) La creciente incidencia de los servicios en la demanda final, en general, sector que se caracteriza por tener un nivel más bajo de productividad y un nivel más alto de gastos de capital por unidad de producción. Debido a la combinación de i) con ii), es difícil acabar con el desempleo y los salarios deben declinar; esto también constituye una condición para el restablecimiento de niveles más altos de utilidades con el fin de obtener la inversión necesaria.

iii) El ritmo acelerado de las innovaciones que afectan al producto y a la producción hace que la reubicación de las manufacturas que requieren mano de obra más intensa y que son más contaminantes en países de bajo desarrollo sea conveniente, a menudo por iniciativa y/o bajo la supervisión de algunos productores de PD. Pero cuando las exportaciones de Ios PED empezaron a penetrar los mercados internos de los $\mathrm{PD}$, principalmente a finales de la década de los años "70, las altas tasas de desempleo de estos últimos provocó la promulgación de nuevas medidas proteccionistas por parte de los gobiernos de los PD en defensa contra la amenaza a sus sectores internos.

iv) Más recientemente, desarrollos tecnológicos más modernos han permitido que algunos P.D recapturen manufacturas que antes requerían intensa mano de obra y cuya producción había sido transferida a los PED durante la década de los años '60 y principios de la década de los años '70.

v) La prematura desintegración de complejos procesos de producción en participaciones o parcelaciones básicas y los decrecientes costos de transporte, comunicación y procesamiento de datos, han contribuido en gran parte a una rápida expansión hacia la internacionalización, por ejemplo, de actividades de las corporaciones multinacionales integradas en todo el mundo, lo que aumenta la interdependencia, pero también tiende a reducir la autonomía de 
las autoridades nacionales. Además, la internacionalización del mercado fomentada por el progreso tecnológico y organizacional definitivamente socava al mecanismo precio en su importante rol de asignador de recursos.

Así y todo, el progreso tecnológico y organizacional ha tenido una crucial importancia al crear, a través de la racionalización, por ejemplo, a) un ejército mundial de reserva industrial... junto con un mercado mundial de poder laboral; y b) un mercado mundial de lugares de producción... en que los países en desarrollo están obligados a competir entre ellos para retener o captar industrias manufactureras orientadas hacia un mercado mundial'15. Ambos acontecimientos contribuyeron a esa reorganización de la producción y distribución que abarca al mundo entero y que, al generar un complejo sistema de interrelaciones, a menudo denominadas internacionalización e interdependencia, está dando forma al orden mundial.

1.5. El proceso de reorganización antes mencionado se ve de alguna manera facilitado por el actual sistema monetario internacional, o lo que implica ese nombre, y varios organismos internacionales. Sin embargo, su fracaso a fines de la década de los años "70 y su subsecuente inestabilidad, constituye la última causa de la crisis mundial que será analizada aquí. El cambio a tasas de intercambio variables, el surgimiento de importantes activos privados líquidos y la falta de coordinación de las políticas monetarias nacionales, han contribuido, todas, a acrecentar la inestabilidad del sistema monetario internacional $y$ han alentado la conducta especulativa en los mercados monetarios. Aunque no parece que esta inestabilidad haya afectado sustancialmente los flujos comerciales internacionales como se esperaba, desequilibrios comerciales y de pagos en grandes escalas siguen caracterizando la economía mundial, con consecuencias dañinas para el crecimiento económico, la inversión y el desempleo, tanto en los PD como en los PED.

Ubicado al centro del sistema monetario creado en Bretton Woods, la incapacidad por parte de EE. UU. de ajustar su tasa de intercambio dio por resultado que la disciplina de la balanza de pagos que tan a menudo ha sido impuesta a otros paises, fue inefectiva en la economía de EE. UU. Otras naciones se vieron ante la alternativa de acumular dólares en sus reservas o aceptar la tasa de inflación de EE. UU., esto es, tolerar suficiente inflación para permitir que los productores norteamericanos ganaran esos dólares nuevamente. Esto significó, de hecho, una 'implícita suscripción de

"Frobel: "The Current Development...", 539. 
las inversiones norteamericanas en Europa y del gran aumento de gastos en el extranjero asociado con la guerra de Vietnam'16.

Para detener la erosión de su posición económica y defender sus reservas, EE. UU. suspendió la convertibilidad del dólar en 1971 y cambió a la tasa de intercambio variable ${ }^{17}$. En principio, esto último debería permitir tasas de inflación variable a los países, pero lo que ha permitido en realidad es que los productores norteamericanos se expandan a costa de otros, y que EE. UU. mantenga su señoreaje sobre la oferta del instrumento de pagos internacionales ${ }^{18}$.

Si bajo el sistema de dólar convertible, EE. UU. había podido antes abastecer al mundo de un bien común, llamémoslo estabilidad económica, su preeminencia comercial reducida y el déficit comercial concomitante no sólo han socavado la capacidad estadounidense de proveer ese bien común, sino que lo han transformado en la causa directa de relaciones financieras internacionales aproblemadas, que a su vez, generaron desequilibrios económicos y paralización mundial. Libre de toda restricción externa, EE. UU. empezó a recuperarse a principios de la década de los años 70, contribuyendo así al primer aceleramiento del proceso inflacionario tanto en el país como en el exterior. La subsecuente devaluación del dólar ayudó a frenar el desequilibrio comercial de EE. UU. y a eliminar cualquier rol monetario que el oro pudiera desempeñar: a fines de la década de los años 50, EE. UU. había consentido a la creación de DEGs sólo para prevenir que se le diera el apoyo suficiente a la propuesta realizada por Francia para la rehabilitación del rol desempeñado por el oro.

Más recientemente, las altísimas tasas de interés aplicadas por los Bancos de la Reserva Federal han acrecentado la capacidad de EE. UU. para obtener recursos de la economía mundial, pero al mismo tiempo, al dificultar aún más la recuperación de los PED, han perpetuado la inestabilidad en la economía. Al no poder asegurar

\footnotetext{
${ }^{20} \mathrm{H}$. O. Schmitt: "International Monetary System: Three Options for Reform", International Affairs, abril de 1974, 50, 2, 197 y 199.

${ }^{27 " . . . a c t i v e ~ p o l i c y ~ m e a s u r e s, ~ a s ~ m u c h ~ a s ~ t h e ~ b u s i n e s s ~ c y c l e ~ i t s e l f ~ c a n n o t ~ f a i l ~}$ to spill from one country into another, whatever the exchange regime"; R. Dornbusch: "Flexible Exchange Rates and Interdependence", IMF .Staff Papers, pp. 30,1 , marzo $1983,24$.

${ }^{18}$ Con el estándar del dólar convertible, el señoreaje es equivalente a la cantidad de dinero neto puesto a disposición de la economia mundial por parte de Estados Unidos, es decir, el deficit de la balanza oficial de pagos. Aun cuando el rápido crecimiento del euro-dólar ha disminuido el grado de precisión de esta equivalencia, no hay duda que el señoreaje de Estados Unidos también ha aumentado. El déficit de la balanza oficial de pago de Estados Uriidos promedí los $\$ 0.6$ mil millones anuales en los años 60 y $\$ 150$ mil millones en los años 70. Ver R. Solomon: "Techniques to Control International Reserves" $y$ otros ensayos en R. Mundell y J. J. Polak: The New International Monetary System (Nueva York, Columbia University Press, 1977).
} 
estabilidad en la economía mundial, y de tal modo justificar el señoreaje estadounidense ${ }^{10}$, este bien común es expresado cada vez más en términos de defensa. La Guerra Fría que resultó ser un instrumento muy útil para establecer la hegemonía de $\mathrm{EE}$. UU., puede resultar útil ahora para recobrar ese sitial.

En resumen, hay aparentemente dos elementos principales en los que se basa la comprensión de la actual crisis internacional.

A corto plazo, los PD, incluyendo EE. UU., que se ven enfrentados a persistentes déficit de la balanza de pagos e intentan limitar sus importaciones, originan así una baja de sus propios ingresos junto con los del resto del mundo. En contraposición con lo que. sucedió en los años 30, sin embargo, EE. UU. puede fácilmente financiar su déficit con dólares, mientras que algunos PED han accedido a los mercados financieros privados. La restricción financiera, entonces, ha sobrecargado las economías europeas más que a ninguna otra. Por supuesto que la demanda mundial podría ser sostenida mediante la expansión de la liquidez oficial internacional; pero las fuentes para la creación de esa liquidez (DEG's y aumento de cuotas del FMI, etc.) están controladas por EE. UU. ${ }^{20}$, que no está necesariamente interesado en detener una crisis de la cual no sólo es el principal causante sino que también el más beneficiado.

Finalmente, existe el problema del endeudamiento de los PED, por ejemplo, su inherente incapacidad para pagar el interés vencido, para no mencionar el pago del principal (ver Sección 3.2). Si no se hace algo drástico en forma rápida para resolver esta situación, todo el sistema monetario internacional que conocemos puede derrumbarse.

2.0. Entre Ios PD, Europa es el área que más ha sufrido por la actual crisis ${ }^{21}$. Esto ha sido así debido a su estructura económica, su persistente $y$, a partir de 1973, su creciente desunión, su rol específico en la división internacional del trabajo, y la posición que ocupa en el sistema económico mundial, incluyendo sus relaciones tanto con los PED como con el bloque oriental.

Como se expuso en el informe Albert y Ball al Parlamento Europeo en 1983, a principios de la década de los 70 Europa Occi-

${ }^{29} \mathrm{C}$. P. Kindleberger: "Systems of International Economic Organization", en D. P. Calleo (ed.): Money and Coming World Order (Nueva York; New York University Press, 1976), pp. 37-38.

ver tambien R. Parboni: The Dollars and its Rivals (Londres, Verso Edition, 1981), p. 108 .

21"The crisis is of international proportions, but its effects are being felt far more severely in the countries... The European economy is not only in a state of stagnation but in decline...", $y$ "the welfare state is restricting (its) growth"; M. Albert y R. J. Ball: Towards European Economic Recovery in the 1980s (Bruselas: European Parliament, Working Documents, 7 de julio, 1983), pp 6. 43 y 24. 
dental se vio enfrentada a tres desafios: la inflación, la crisis energética y la creciente competitividad japonesa junto con las manufacturas de los Países Recientemente Industrializados (PRI), a los que Europa respondió reduciendo el porcentaje de PNB correspondiente a la inversión y aumentando aquel correspondiente al consumo total entre 1973 y 1983 . Tomando en cuenta que durante ese mismo período los sueldos en Europa crecieron a un ritmo de $2,5 \%$ al año ${ }^{22}$, mientras se estancaban en EE. UU. y subían menos que el PNB en Japón, y que los demás descuentos aplicados a los sueldos así como los impuestos fueron los más altos del mundo, no es de sorprenderse que Europa perdiera tres millones de empleos mientras que EE. UU. creaba 15 millones. Sólo en 1984, en EE. UU. se han creado 3 millones de empleos, pero los sueldos semanales en términos reales sólo subieron un 1,8\% entre mayo de 1982 y mayo de 1984. Aún más, las utilidades netas en 1980 (sobre el capital) de las industrias no-manufactureras de petróleo, fueron del orden del $11,5 \%$ para las compañías norteamericanas; $13,8 \%$ para las japonesas y menos $0,1 \%$ para las europeas, hecho que obligó a reducir la inversión a cerca del $3 \%$ a principios de los años 'so. El resultado es que:

i) Sólo algunos de los países de la CEE pudieron reducir sus tasas de inflación a niveles comparables con EE. UU. y Japón;

ii) El desempleo ha aumentado 2,5 veces más que en EE. UU. y no hay esperanzas que esto pueda ser sustancialmente reducido en el futuro próximo. De hecho, los más recientes cálculos colocan el promedio de la tasa de desempleo laboral de los Seis en un 11,2\% para el período 1983-90 (fluctuando entre 19,1\% para Bélgica y $8,5 \%$ para Alemania Occidental), casi el doble que para el período 1975-83, que fue de $6,8 \% \%^{23}$. Para Europa entera, la cifra oficial para el desempleo es de 19 millones y va en aumento, mientras que para todos los países $O C D E$ alcanza un total de 35 millones;

iii) Las inversiones disminuyeron de un porcentaje promedio de la tasa de crecimiento de 5,7 al año a 1,6 en la década de los 70, hasta valores negativos a principios de la década de los 80. Esta baja también afecta al sector energético. El bajo precio del petróleo rejnante ha ayudado a reducir la inversión en nuevas y viejas fuentes de energía así como en medios para ahorrar energía, de manera que no es improbable que haya una tercera crisis del petróleo hacia fines de la presente década ${ }^{24}$;

ఇ Su crecimiento dejó de ser más rápido que su productividad sólo en 1982; Ibid., p. 23.

ॠconomist Intelligence Unit: The Major European Economies, 1984-90, EIU Special Report No 173.

${ }^{34}$ Albert y Ball, 86-87, informan que mientras la CEE piensa invertir en energia un equivalente al 2,2\% del PNB (de hecho 1,6 en 1980), la inversión japonesa será del $3 \%$ y la de Estados Unidos de $4 \%$. 
iv) Los déficits fiscales han aumentado de un 0,5\% del PIB durante el periodo $1968-73$ a 3,71\% durante 1974-78, y, por último, más del 5,0\% durante 1981-83. Entretanto,

v) Los pagos obligatorios al servicio de seguro social han aumentado y están ahora alrededor de 13 puntos más altos que en EE. UU. ${ }^{25}$ Por último,

vi) Entre 1973 y 1983 los Seis han perdido, en conjunto, 6 puntos de su participación en el mercado mundial de manufacturas, principalmente en favor de EE. uU. y de Japón ${ }^{26}$.

Decir que 'parte de la debilidad europea es consecuencia de las características poco comunes de la recuperación de EE. UU.'27, no minimiza la posición actual de Europa, pero sirve para destacar algunas de las otras dificultades a las que se ve enfrentada dentro de un sistema de creciente interdependencia.

2.1. Los estados benefactores europeos más avanzados - cuyo gasto público constituyó un 32\% del PIB de la CEE en 1960 y un $51 \%$ en $1983 ; 28 \%$ y $36 \%$ en Ee.uu.; $21 \%$ y $35 \%$ en Japón- dieron origen a los mayores déficits cuando la baja de crecimiento económico causó alzas en el gasto social, principalmente por compensación de cesantía y servicio de la deuda, y bajas en los ingresos fiscales simultáneamente. Dadas las restricciones externas impuestas a la política monetaria europea, los intentos para reducir el déficit no podían tener exito. Además, como estas políticas de restricción han sido aplicadas en forma simultánea por parte de varios gobiernos, sus efectos negativos se ven mezclados por la estrecha integración de las economías en cuestión. Para reducir esos déficit, se han limitado las inversiones. Si Europa ha podido mantener hasta ahora su stándard de vida, ha sido a costa de nuevas inversiones y, por lo tanto, del crecimiento a futuro.

Además, un gobierno con altos gastos de beneficencia genera elementos rígidos en la estructura y la utilización del trabajo y ast contribuye a perpetuar la cifra de desempleo prevista en un $11,2 \%$ de la fuerza laboral de los Seis durante el período restante de esta década ${ }^{28}$. Por supuesto que los efectos negativos generados por esta alta tasa de cesantía los constituyen el afán proteccionista y la virtual paralización del progreso tecnológico, dos aspectos que reducen la competitividad europea y la posibilidad de una más rápida recuperación económica. En otras palabras, el alto costo del trabajo ayuda a originar cesantía que, a su vez, reduce los incentivos para el progreso tecnológico.

Istbid., pp. 10-25.

${ }^{20} \mathrm{EIU}:$ The Major European Economies.

mOstry: "The World Economy", p. 540.

${ }^{23} \mathrm{EIU}$ : The Major European Economies. 
Si los déficits fiscales han alcanzado niveles que no se pueden ya tolerar - de 0,6\% del PIB de la CEE entre 1968 y 1973, a más del $5,0 \%$ en los años ' 80 - la tradicional política coordinada de estimular el consumo, del modo que fue utilizada en los años 1972-75, ya no es viable; la única alternativa es financiar nuevas inversiones provenientes de fuentes que no sean públicas ${ }^{29}$, y aumentar las exportaciones, incluso aquellas hacia los PED.

Vale decir que mientras se dieron condiciones de rápido desarrollo económico, el financiamiento de los costos de la beneficencia resultó fácil mediante leves variaciones que le correspondían de las deducciones obligatorias del PIB; bajo la paralización o cero crecimiento económico, sus costos han aumentado continuamente debido a: i) el número cada vez mayor de personas de edad acogidas a jubilación, cuidados de salud $\mathrm{y}$, por supuesto, más pagos por concepto de cesantía, y ii) a la disminución de contribuciones salariales, a un ritmo que ha superado a aquel de la riqueza nacional. Para financiar los déficit resultantes, se ha reducido la inversión (fenómeno de "crowding-out") y últimamente ha surgido un flujo de capital neto hacia EE. UU.

2.2. A pesar que Europa, como un todo, constituye una entidad económica a grosso modo equivalente a aquella de EE. UU., tanto en cuanto a oferta como a demanda, la CEE ni siquiera representa un mercado para los productos, servicios, y factores de producción europeos. Bajo el impacto de la crisis, las tendencias centrífugas y tentaciones nacionalistas están amenazando seriamente el progreso hacia un mercado común que se había estructurado hasta principios de los años '70.

Al mismo tiempo, han aparecido claramente dos restricciones estructurales de importancia: por una parte, la interdependencia de las economías europeas ha alcanzado tales niveles que ni siquiera sus países más poderosos pueden mantener la esperanza de expanderse por su cuenta (ver el intento del Reino Unido en 1973, Alemania Occidental hacia fines de los años '70, y Francia, a principios de los años '80); por otra parte, la dependencia externa ha crecido tanto que cualquier política común o armonizada, que no tome en consideración este aspecto en forma cuidadosa y explícita, resulta inefectiva.

La primera restricción anula la teoría de un motor interno para la recuperación europea, la segunda, la de un motor estadounidense para la recuperación, ya que, sin un esfuerzo coordinado internamente, ningún estímulo externo sería suficiente.

La desunión interna ha fortalecido la dependencia de Europa de ŁE. UU. Y ha fomentado la esperanza europea de que sea EE. UU. el

${ }^{20}$ Albert y Ball: Towards European Economic Recovery, 84. 
que actúe como motor para su recuperación. Este no es el caso por dos razones. Primero, aún considerando solamente el efecto positivo de la recuperación de $\mathrm{EE}$. uU., vale decir, el estímulo que 'otros países OCDE... están recibiendo del crecimiento de las exportaciones hacia EE. UU.', lo máximo que puede alcanzar es un tercio de su crecimiento PNB entre el año pasado y este año, crecimiento que para Europa fue de un $2 \%$ en la segunda mitad de 1983 y se espera que se eleve a tasas de un 2,0 a $2,5 \%$ de ahora en adelante ${ }^{30}$. Segundo, la recuperación de EE. UU. no es necesariamente sostenible:

a) porque el impacto negativo causado por la contracción fiscal, que más probablemente tendrá que ser implementada más temprano que tarde para frenar el déficit fiscal, puede que no alcance a ser compensado por una sustancial y perdurable reducción de las tasas de interés reales, y b) porque cualquier baja considerable del dólar haría necesario que se aplicara una política monetaria más estricta $y$, por lo tanto, tendría lugar un alza aún mayor de las tasas de interés. Aunque una baja del dólar redundaría en una mayor competitividad internacional por parte de EE. UU. (a menos que resulte estar más que compensada por los efectos inflacionarios) $y$, por lo tanto, en menos importaciones así como mayores exportaciones, las tasas de interés más altas atraerían más capital extranjero. En ambos casos, las posibilidades de recuperación de Europa se verían socavadas.

2.3. La agresividad de la penetración japonesa en Europa, principalmente de maquinaria y de equipo de transporte, coincidió con el principio de la crisis general, y así sorprendió al viejo continente aún más dividido e incapaz de articular una respuesta común como no fuerar las crudas reacciones proteccionistas. Siendo que anteriormente había prestado poca atención al fenómeno económico japonés, Europa estaba mal preparada para lidiar con él. De hecho, en las relaciones trilaterales entre EE. UU., Europa y Japón, son aquellas entre estos dos últimos países las que han sido consideradas las más débiles por largo tiempo, contrastando con aquellas más estrechas entre Japón y EE. UU. y entre Europa y EE. UU. 31 A pesar que el comercio entre Europa y Japón aumentó en forma acelerada durante los años '60 -entre 1960 y 1970 las exportaciones japonesas se sextuplicaron (de $\$ 0,4$ a $\$ 2,4$ mil millones), pero sus importaciones solamente casi se cuadruplicaron (de $\$ 0,5$ a $\$ 1,9$ mil millones), de manera que la cek-9 se equilibró apenas- el valor de las importaciones de Japón correspondió a menos de un $1 \%$ del consumo industrial de Europa hacia fines de los años 70 . El creciente desequilibrio a favor del Japón durante esa década (en los

${ }^{30}$ OCDE Economic Outlook 35, julio de 1985, 7 y 10.

${ }^{\mathrm{s} M}$. Hanabusa: Trade Problems between Japan and Western Europe (Farnborough: Saxon House, 1979), ix-x. 
años 70 las exportaciones japonesas a la CEE aumentaron 8 veces y sus importaciones de la CEE, 4 veces, como en los años 60 ) se debió casi exclusivamente al deterioro de la balanza comercial de la Comunidad en el campo de las manufacturas sofisticadas ${ }^{32}$. Como se aprecia, Europa se ha concentrado más en el desafío que representan las exportaciones japonesas y no tanto en la penetración del mercado japonés. A pesar del excelente desempeño comercial a partir de principios de 1980, la continua subvaluación del yen - probablemente ocasionada por enormes flujos de capital al exterior, principalmente a $\mathrm{EE}$. Uu., que tienen su origen en las tasas de interés diferenciaclas entre estos dos países- ha ayudado a fortalecer la capacidad exportadora de Japón.

$\mathrm{Si}$ es verdad que la exportación japonesa a gran escala de maquinaria y equipos a la Comunidad europea pueda influir en uno de los sectores considerados problema dentro de la Comunidad'33, la incapacidad de esta última para montar una campaña comercial dirigida al propio mercado japonés sólo se puede explicar con la desunión europea, aún tomando en cuenta que, a diferencia del comercio entre Japón y EE. UU., el comercio entre Japón y la CEE es básicamente horizontal... y por esto el desequilibrio comercial es de naturaleza más estructural'sa. Esa desunión ha favorecido la estrategia japonesa de penetrar el mercado europeo de vehículos de pasajeros, empezando por los países periféricos, no-productores y los países pequeños, de menor producción, relativamente más abiertos, para después continuar hacia los países de mayor producción. Más tarde, las opiniones sustancialmente diferentes de los miembros de la CEE con respecto a cómo protegerse contra las importaciones e inversiones japonesas, han hecho que sea difícil obtener una posición común de parte de la Comunidad tanto para este sector como para la industria de los televisores. Las inversiones japonesas en el mercado automotriz y de televisores europeo, como lo hicieran la mayoría de las norteamericanas anteriormente ${ }^{35}$, han sido orientadas a asegurar y expander la porción del mercado europeo establecido por el comercio internacional, más que a fomentar su capacidad de exportación. Los países europeos han sido incapaces de elaborar una posición común y es así que, como las exportaciones, las inversiones japonesas han establecido una posición firme en algunos países (el Reino Unido para automóviles y más aún para televisores) desde donde abastecen al resto del continente. Por ende, las diversas respuestas al desafío japonés ponen en peligro la cohesión de la unión aduanera de la Comunidad, a

${ }^{32}$ G. Shepard: "The Japanese Challenge to Western Europe's New Crisis Industries", The World Economy, 4, 4, diciembre de 1981, 377.

"Isid., 378.

${ }^{3}$ Hanebasa: Trade Problems..., 61 y 82.

sálbid., 36. 
pesar que un mercado más amplio constituye; potencialmente, parte de la solución a este desafío'so.

2.4. Los profundos cambios, la mayoría de los cuales son irreversibles, que están dando nuevas formas a la economía mundial, y el mecanismo de crecimiento en el que esta última se basa, requieren de uná reestructuración a gran escala. Esto es tanto más difícil para Europa, cuanto que ha quedado con grandes cicatrices debido a la crisis mundial, y parece incapaz de volver a alcanzar las altas tasas de crecimiento a las cuales estaba acostumbrada, o de reducir su vulnerabilidad, tan vívidamente dejada al descubierto por dos intensos impactos petroleros, por la recuperación norteamericana, y por la competencia japonesa. Dado que los cambios estructurales de una economía estancada requieren de un grado mucho mayor de contracción total de las actividades económicas'87, las rigideces socio-económicas europeas complican aún más su reestructuración industrial con su básica necesidad de una mayor acumulación ${ }^{38}$. Sin embargo, esto último es crucial para contrarrestar la persistente baja en las inversiones industriales fijas con relación al porcentaje del PNB y así posibilitar adaptaciones protectoras y el manejo de la inversión de acuerdo a nuevos esquemas. Esta última, sin embargo, no sólo tiene que aumentar la mecanización y acelerar el proceso de acumulación de inventario de planta, sino que debe poder ampliar la capacidad de producción y crear nuevos empleos.

En principio, por lo tanto, Europa se ve enfrentada a tres tareas que no sólo son difíciles sino que, por lo menos en el corto plazo, son hasta cierto punto contradictorias: i) penetrar sectores de tecnología más avanzada para poder competir con EE. UU. y Japón, tarea que requiere no tanto mayor investigación y desarrollo como una mejor coordinación de los asuntos nacionales; ii) desarrollar los servicios necesarios para controlar el proceso de descentralización territorial y sectorial de las producciones importantes de los PED, y iii) generar algún tipo de empleo para reducir el número de personas sin empleo que alcanza los 19 millones y que, por una parte

"Shepard: "The Japanese Challenge...", pp. 381 y 387-89.

${ }^{37}$ M. Michalski: "The Need for Positive Adiustment Policies in the 1980's, Intereconomics, 18, 1, enero-febrero de 1983; Michalski también escribe que "there is either a virtuos circle of micro-economic flexibility and macro-economic stability or a vicious circle of rigidity and instability", (Ibid).

${ }^{35}$ R. D. Muldoon, el exuberante Primer Ministro neozelandés hasta julio de 1984, primero sostuvo que mientras "economic analysis tells us change is better managed in times of growth, political analysis gives us a somewhat different message", pero añadió inmediatamente que "putting any change into effect can be done as the recovery proceeds and thereby gives us a little flexibility to adjust to change" (Rethinking of the Ground Rules for an Open World Economy", Foreign Affairs, 6l, 5, yerano de 1983, 1079). 
amenaza la estabilidad socio-política $y$, por la otra, absorbe parte de los recursos que son los mismos que se necesitan para financiar la política de ajuste en general. Esta última tarea es tanto más urgente cuanto que hay una gran cantidad de jóvenes desempleados lo que implica también un ajuste o adaptación del actual sistema educacional que no ayuda necesariamente a igualar la oferta real de trabajo con la posible demanda.

El abordaje de estas tareas va a afectar necesariamente el rol que desempeñan los gobiernos en la economía nacional e internacional, así como la permanencia de un sistema de libre mercado en el que se ha basado, en gran parte, el actual orden económico mundial. De este modo si los gobiernos de los diversos países de Europa por no decir nada del Gobierno Europeo, han de transformarse en 'estados de desarrollo'39, vale decir que si van a diseñar e implementar las políticas de ajuste que les permitirán reestructurar sus economías y superar la actual crisis mundial, entonces el comercio internacional debe ser de algún modo internalizado, haciendo que sean necesarios $e$ incluso naturales los acuerdos con otras entidades territoriales comparables. Estos acuerdos son el único posible instrumento con el que las actividades de las corporaciones multinacionales y las transacciones con moneda europea pueden ser efectivamente reguladas. Además, parece que EE. uU. ya ha decidido movilizarse a lo largo de líneas similares, evitando así el GATT, y estableciendo una serie de acuerdos diferentes con cada país o con grupos de países pequeños, para asuntos específicos ${ }^{40}$.

2.5. Nadie duda ya que estas políticas de ajuste, aunque son necesarias, requieren de una incalculable reasignación de capital y de trabajo. Y como esto implica también temores, los gobiernos a menudo son incapaces de actuar ante la resistencia que éstos generan. Las postergaciones se transforman en una solución política, aún en los casos en que la introducción, en forma planificada, de los acontecimientos inevitables constituye la única manera de limitar su impacto negativo.

Una idea de los cambios que acaecerán se puede obtener a partir de las tendencias actuales en EE. Uu., como las ve el Bureau of Labour Statistics. Nos guste o no, esta perspectiva sugiere enfáticamente lo que el futuro de Europa puede albergar:

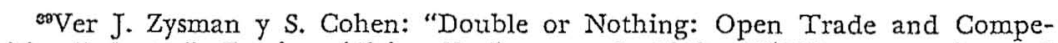
titive Industry", Foreign Affairs, 61, 5, enero de 1983, 1117-19, para quienes el estado de desarrollo "pursues clearly defined goals of industrial expansion" tratando "to create enduring advantages and to alter their national place in the world economic hierarchy". Buenos ejemplos de este tipo de estado lo constituyen la mayoría de los Nics y, por supuesto, Japón y Francia (Ibid.).

${ }^{\circ}$ Durante el verano de 1984, el señor M. B. Smith, representante del comercio de los Estados Unidos, viajó por el mundo tratando de lograr acuerdos con grupos de palses, tanto PSDS como PSMD, en áreas específicas. 
i) Cerca del $75 \%$ de todos los nuevos empleos previstos hasta 1995 provendrán de las industrias que prestan servicios. Solamente las industrias de cuidados médicos (vale decir, consultores, servicios de personal, relaciones públicas, sistemas de seguridad, y servicios de computación y procesamiento de datos), recreación y hotelería, proveerán uno de cada tres nuevos empleos en la década que viene, de manera que en 1995 estos servicios proporcionarán 31 millones de empleos, un cuarto del empleo total supuesto.

ii) Sólo uno de cada seis nuevos empleos provendrá de manufacturas, de modo que, aun cuando el actual porcentaje correspondiente a manufacturas en las cifras actuales de empleo total puede mantenerse más o menos estable ( $19 \%$ incluyendo la minería y la construcción de un $25 \%$ a fines de los años ' 50 ), su sector de crecimiento será aquel correspondiente a la nueva producción de alta tecnología ${ }^{41}$. Durante la recesión, las manufacturas perdieron 2,3 millones de empleos, pero generaron 1,5 millones, en su mayoría, nuevos.

iii) Actualmente, $25 \%$ de las personas están empleadas en industrias productoras de bienes, manufacturas más minería y construcción; el $75 \%$ restante está empleada en servicios. Aunque los servicios tradicionales (servicios públicos al detalle, transporte, hoteles y restaurantes) no han aumentado y pueden incluso estar declinando, el sector de información (oficinistas, profesores, contadores, agentes de seguros, abogados, empleados de gobierno, programadores y procesadores de datos) se ha expandido rápidamente y se espera que seguirá haciéndolo, de modo que actualmente absorbe un $65 \%$ de la fuerza laboral de eE. uU. y genera más de la mitad de su ingreso personal ${ }^{42}$.

Durante 19S2, Ia banca empleó un número equivalente de personas que el sector de equipos de transporte (1,6 millones); restaurantes y otros detallistas emplearon 10 veces ese número. Dentro de una década más o menos, todos los productos manufacturados que necesita EE. UU. se supone que serán producidos por menos del $10 \%$ de su fuerza laboral.

iv) Ya que los sectores que crecen más rápido generan por lo común trabajos de baja productividad y por lo tanto, pagan me-

MM. Geldens, de McKinsey y Cía., en su propuesta "Towards Fuller Employment", publicado por The Economist, del 28 de julio de 1984, establece que, de los 19 millones de nuevos empleos creados en Estados Unidos durante los años 70 , sólo un $5 \%$ corrcspondió al sector manufacturas, un $11 \%$ a industrias productoras de bienes, alrededor de un $12 \%$ en el sector de servicios tradicionales y un $72 \%$ (cerca de 14 millones de empleos) en el sector de información, incluyendo 3 millones de empleados en su mayor parte por gobiernos estatales y locales (Ibid., 19).

s'Tbid. 
nos salarios que aquellos que declinan en crecimiento ${ }^{43}$, este proceso de 'desindustrialización' de la economía plantea un gran desafío en cuanto al estándar de vida de una porción significativa de la fuerza laboral. El rápido aumento del interés por trabajar medio-tiempo, medio año, con horarios flexibles, por una educación continuada y/o para adultos, así como el deseo de jubilar a temprana edad, pueden contribuir aún más al estancamiento del ingreso monetario personal, aunque no necesariamente al ingreso familiar, si se toma en cuenta el creciente número de cónyuges activos en el mercado laboral.

v) Un-probable y muy interesante resultado relacionado con el sector de informaciones es que en él el capital y el trabajo pueden mantenerse unidos... como lo hicieron en la agricultura; parece que muchos de nuestros hijos tendrán la oportunidad de trabajar en pequeñas firmas como socios empresariales en vez de en calidad de empleados descontentos ${ }^{\prime 45}$. Si en principio las utilidades de capital pudieran, entonces, compensar las pérdidas laborales, la absorción hacia el sector información requiere que se efectúen caros programas de entrenamiento o reentrenamiento. Bajo estas condiciones, el sindicalismo se hace más difícil y las organizaciones laborales deben revaluar su rol y reestructurar sus estrategias.

vi) La expansión de los PED (vale decir de los PRI) en cuanto a la exportación de sus productos manufacturados a otros PED (este comercio Sur-Sur alcanzó al 36\% de toda la exportación de manufacturas de los PED en 1979) ${ }^{46}$ y a los PD (comercio Norte-Sur), claramente representa otro aspecto de la desindustrialización (para algunos es incluso la causa de esto último) y ciertamente la más amenazadora. Sin embargo, entre 1960 y 1979 , la porción de las exportaciones mundiales correspondientes a los PRI aumentó sólo de 8 a $8,7 \%$, a un ritmo de crecimiento promedio anual de $14,8 \%$, levemente superior a aquel que tiene relación con las exportaciones mundiales ${ }^{4 T}$. Durante los años 70, las importaciones de productos manufacturados para consumo efectuadas por los OCDE aumentaron

${ }^{13} \mathrm{El}$ argumento de que la expansión de servicios ha contribuido a la disminución de la productividad del pafs es refutado por la Oficina de Estadísticas Laborales de Estados Unidos.

«Para una extensa exposición de este fenómeno, que al principio se creyó que afectaba principaImente al Reino Unido, ver F. Blackaby (ed.): De-industrialisation (Londres: Heinemann, 1979).

${ }^{45}$ Geldens, "Torvards Fuller Employment", 19.

${ }^{10}$ Contrario a lo que se creía anteriormente, A. H. Amsden indica que el comercio Sur-Sur es relativamente más capacidad-intensivo que capital-intensivo $y$, por lo tanto, no debería mirarse más como un desperdicio; "De-skilling", 'Skilled Commodities and the NICs' Emerging Competitive Advantage', AEA Papers \& Proceedings, 73, 2, mayo de 1983.

${ }^{47}$. Kebschull: "Economic Relations with Newly Industrializing Countries", Intereconomics, 18, 6, noviembre/diciembre de 1983, 287, Tabla 1. 
en valor nominal casi 15 veces, y aquellos de los PED casi 11 veces; la penetración de mercados de estos últimos aumentó de $15,5 \%$ a $19,1 \%$ a una tasa del $2,4 \%$ al año entre 1970 y 1980 . La participación de las exportaciones de los PED en el aparente consumo de productos manufacturados en todos los PD promedió un 3,4\% en 1980 (aumentando del 1,7\% en 1970), es decir, 4,5\% en la CEE, $2,5 \%$ en Japón, 2,9\% en EE. uv. Durante 1982, el valor de las manufacturas exportadas por los PED alcanzó los $\$ 40,3$ mil millones de un total de $\$ 198,7$ mil millones ${ }^{48}$. Entre los PED, la penetración de mercados por parte de los 'exportadores de los PRI del Lejano Oriente creció más rápidamente $(8,0 \%$ anual), mientras que la de América Latina fue la más lenta $(0,4 \%)^{49}$. Hong-Kong, Taiwán y Gorea exportaron un poco más de la mitad de los bienes manufacturados de los PED a los OGDE durante 1980 (América Latina escasamente un $16 \%$ ), y $72 \%$ de bienes de consumo, principalmente (América Latina casi un $7 \%$ ) ${ }^{50}$. De estos bienes exportadores por los PED, $46 \%$ fueron comprados por EE. UU. y $36 \%$ por la $\mathrm{CEE}^{51}$. Sin embargo, estas importaciones parecen haber causado un efecto muy leve de sustitución de empleos, da la impresión que menos de un $0,25 \%$ de la fuerza laboral total de fines de los años $70^{52}$.

Las condiciones principales que dan lugar a esta revolucionaria transformación de la economía de EE. UU. son, brevemente:

i) alta movilidad de los factores de producción, incluyendo el trabajo tanto sectorial como espacialmente;

ii) flexibilidad salarial y sindicalismo moderado;

iii) un nivel de educación relativamente alto;

iv) un ambiente institucional que responda, tal como abundante capital empresarial, desregulación, etc.; y

v) la disponibilidad por parte de las minorías y los trabajadores ilegales para absorber en gran medida los costos de transformación.

4SUNCTAD: Protectionism and Structural Adjustment, $\mathrm{TD} / \mathrm{B} / 88 \mathrm{I}$ (Parte Ir), 2, febrero 1984, 9, Tabla X.

${ }^{*} \mathrm{Y}$. Cable: "Trade Policy Towards the Nras-Options for EEG", xDs Bulletin, 14, 3, 1983, 34, Tabla 2 y 35, Tabla 3. Ver también H. Chenery y D. Keesing: "The Changing Composition of Developing Countries Exports", en S. Grossman y E. Lundberg (editores): The World Economic Order (Lonđres: Macmillan, 1981).

EoD. B. Keesing: "Linking Ūp the Distant Markets: South to North Exports of Manufactured Consumer Goods", AEA Papers \& Proceedings, 73, 2, mayo de 1983, 338 y 339 , Tabla 1.

sI Ibid.

${ }^{82}$ C. Hamilton y M. E. Krenin: "The Structured Patterns of LDCs' Trade in Manufactures with. Individual and Groups of Das", Weltwirtschafliches Archiv, $116,2,1980$. 
2.6. Europa no está en la posición más favorable para aceptar este proceso ineludible de desindustrialización o de utilizarlo para regenerar su vida económica, así como para aumentar su integración. Ambas metas están ligadas y lograrlas exige una reorganización de las prioridades de Europa en lo que conciernè también sus relaciones exteriores. De hecho, si la desindustrialización es el resultado de la industrialización cada vez más competitiva de parte del Tercer Mundo, entonces evidentemente se deberían ampliar las actividades de mutuo beneficio dentro de un sistema controlado de interrelaciones (ver última sección).

En todo caso, si la reacción de Europa en el pasado constituye alguna indicación de su capacidad para enfrentar este desafío, hay pocas razones para estar optimista a menos que uno crea firmemente en la capacidad de aprendizaje, así como en sistemas de mayor envergadura. Un buen ejemplo de cómo no enfrentar el desafío se puede apreciar en el enfoque aplicado hoy en día de tratar de mantener la obsoleta mezcla de 'planta temporalmente en operaciones'. Más de 100 corporaciones de acero operan en Europa, de las cuales sólo una o dos daban utilidades a principios de esta década. Cada vez menos capaces de competir con la producción extranjera y operando a la mitad de su capacidad, ellas han obtenido no menos de $\$ 70$ mil millones en subsidios, to que sería suficiente para financiar la más completa reestructuración del sector ${ }^{53}$. Por medio de la utilización de la más avanzada tecnología, el manejo de la capacidad excedente ya no sería necesario y el sector podrá haber producido las 100 millones de toneladas de acero necesarias a un costo competitivo, pero empleando 150.000 personas en vez del medio millón de 1970.

Como los subsidios, el proteccionismo y la devaluación constituyen medios para exportar desempleo y mantener utilidades ${ }^{54}$, y ha sido el proteccionismo la respuesta de Europa a la exportación de textiles y vestuario por parte de los PRI. En consecuencia, las barreras no-tarifarias de la CEE en lo que concierne a textiles y artículos de textiles fueron las más altas impuestas en 1982 a las exportaciones manufacturadas de los PED por parte de los PD. Sin tomar en cuenta el ítem armas y municiones, las siguientes barreras más altas fueron aquellas aplicadas a calzado, tocados, plumas preparadas por parte de EE. UU.55, 10 que permitió que Alemania Occidental, Japón e Italia siguieran siendo los mayores exportadores en 1982. Estas exportaciones están dirigidas principalmente hacia otros PD, de los cuales se mantienen fuera productos más baratos provenientes de PED mediante acuerdos multifibra. Entretanto, Ia

${ }^{5}$ Geldens, "Towards Fuller Employment", 18.

"Zysman y Cohen: "Double or Nothing", 1123.

${ }^{5}$ UNCTAD: Protectionism, Trade Relations and Structural Adjustment, Belgrade Conference, TD/274, junio de 1983, 17. 
introducción de nuevas tecnologias en este sector en muchos PD ha casi anulado la ventaja de la mano de obra barata de los PED.

No obstante, el desempleo en Europa se mantiene a niveles que se consideraban inaceptables hace sólo unos años, y a los países de la ceE no les queda más que aceptar cada vez mayores restricciones que, a su vez, frenan inevitablemente el crecimiento y la transformación. La faita original sigue radicada en la Política Agrícola Común, cuya profunda revisión es reconocida por todos como una condición ineludible que solamente la cortedad de vista de algunos gobiernos y de parte de la burocracia europea, sigue postergandos6.

Como lo señala el plan Albert y Ball, los miembros de la CEE deben llegar a un acuerdo con respecto a un aumento concertado de la inversión pública, de tal manera de aumentar.su PNB en un $1 \%$ durante tres años ${ }^{57}$. E1 monto necesario alcanza el orden de los 15 mil millones de UMESs, equivalente al $3 \%$ de las inversiones fijas bruto de la GEE, durante el primer año, declinando rápidamente en los años siguientes, dado que por cada $1 \%$ de aumento del PNB los déficits fiscales tienden a disminuir por una cantidad equivalente a un $0,2-0,3 \%$ del PNB. Las características principales del plan son las siguientes:

i) Coordinación de los esfuerzos; existe claramente un multiplicador de eficiencia comunitario que, simulacros con el Comet III, estiman en 2-4 puntos en la tasa de crecimiento y de un $20-66 \%$ de mejoramiento en la balanza neta externa ${ }^{58}$.

-ii) Reconocimiento del hecho que una recuperación basada en una transformación estructural ya no puede resultar del manejo de la demanda, sino que debe basarse en un aumento de la inversión que no esté financiado por gasto deficitario. Esto se lograria mediante un préstamo suplementario de la Comunidad, que se podría obtener principalmente a través del Banco de Inversiones Europeas y por medio de la aplicación de impuestos a materias primas norenovables, como fue sugerido por Goldens ${ }^{59}$. Los precios más al-

${ }^{60}$. Pearce, "Reform of the Common Agricultural Policy and the Third World", de C. Stevens (ed.): EEC and the Third World: A Survey of Hunger in the World (Londres: Hodder and Stoughton, 1982); S. Harris, A. Swinbank and G. Wilkinson: The Food and Farm Policies of the European Community (Chichester: John Wiley \& Sons, 1983), Cap. 14; C. Mackel, J. Marsh y B. Revell: "The Common Agricultural Policy", Third World Quarterly, 6, I, enero de 1984.

"Blanchard y Dornbusch, "U.s. Deficits", 90 y 106, sostienen que "a temporary and modulated fiscal expansion in Europe still appears both desirable and feasible", porque "as long as fiscal expansion remains high in the us and lower in Europe, the appreciation of the dollar will remain".

${ }^{2}$ Albert y Ball: Toward European Economic Recovery, 38-39 y 57-59, Tablas 7,8 y 9 .

"Geldens, "Towards Fuller Employment", 20. 
tos de las materias primas obligaría a los usuarios a ahorrar y una parte de los ingresos por concepto de impuestos podría ser devuelto a los productores de loS PED para ayudarlos a diversificarse.

iii) Dirigir la inversión hacia proyectos comunes que involucran el uso de tecnología avanzada y requieren de la cooperación entre las empresas de los diversos países de Europa (ver el Proyecto Esprit de reciente aplicación). Aunque el gasto de los países de la CEE en investigación y desarrollo no es mucho menor que aquel de EE. UU. y casi el doble del de Japón, éste se torna ineficiente por las divisiones internas. Como resultado de éstas, en Europa se empiezan a apreciar graves demoras en diversos sectores ${ }^{60}$. Más aún, deben establecerse leyes e infraestructura institucional comparables con el fin de generar un ambiente que sea más conducente a los esfuerzos y a las actividades en común.

iv) El establecimiento de las condiciones necesarias para que el Sistema Monetario Europeo (SME) logre su principal objetivo, al favorecex el desarrollo económico y la interdependencia intra-europea, y crear una 'zona de estabilidad monetaria en Europa' que sirva de base para una creciente integración económica ${ }^{01}$. Aunque se está de acuerdo que las operaciones del SME han tenido hasta ahora un efecto moderador en la variabilidad de la tasa de intercambio de las monedas que intervienen y en la prevención de una mayor divergencia en sus desarrollos económicos, se debe dar un nuevo ímpetu a la unidad monetaria europea en vez de esperar que se produzca una convergencia espontánea y significativa en las políticas económicas de los estados miembros, de la cual, en todo caso, no existen señales. El fortalecimiento del SME también resultaría a partir de la adopción del 'Plan Marshall' de Albert y Ball para el sector energético y para una política regional, el primero para reducir la dependencia de fuentes extranjeras $y$, por lo tanto, aflojaría las restricciones de la balanza de pagos, y la segunda para una mejor distribución de los costos de las políticas de ajuste. Al ayudar a las áreas más débiles y al generar flujos financieros significativos, probablemente a través del financiamiento de proyectos, estas políticas también ayudarían a reforzar el $S M E^{82}$.

Este enfoque implica lo siguiente:

WVer data entregada por Albert y Ball: Towards European Economic Recovery. 121, Tabla 10.

${ }^{61} \mathrm{R}$. Triffin: "The European Monetary System and the Dollar in the Framework of the World Monetary System", Banca Nazionale del Lavoro Quarterly Review, 142, septiembre de 1982; y "L'avenir de l'ECU", San Paolo ECU Newsletter, marzo de 1984; C. Cecchi: "The European Monetary System and the Ex. ternal Financing of less developing countries", THEMA Towards a European Monetary Fund (Torino, Italia: San Paulo Bank, 1980).

${ }^{\circ}$ Sobre este punto ver Parboni: The Dollar and its Rivals, 156 y 163.68; respecto de la relación entre el SME y el dólar. 
i) La contención del poder comprador de la mayoría de los europeos con el fin de:

a) Salir adelante con niveles menores de productividad, resultado de la desindustrialización;

b) Contribuir a la reducción del desempleo; y

c) Liberar recursos para el financiamiento de nuevas inversiones, incluyendo investigación y desarrollo, y para ayudar al servicio de la deuda externa de los PED, el esquema $1 / 3 \times 3$ propuesto bajo el ítem 3.2 más adelante.

Esta contención está compensada por más descanso, acuerdos laborales más flexibles, mejor calidad del medio ambiente y mejores condiciones en la posesión de acciones, así como en la representación dentro del directorio.

ii) Aumento del rol del estado al establecer nuevas reglas del juego y al estructurar efectos de mercado -el estado para el desarrollo-, pero disminuyendo sus funciones de benefactor.

iii) Reemplazo explícito del sistema de mercado abierto por un sistema de intercambio controlado que facilitará la adaptación al proceso de ajuste y el rechazo de la idea que las estructuras sociales y económicas debieran ser determinadas por el mercado internacional ${ }^{63}$.

iv) La combinación de las diversas economías nacionales en un șistema continental que, mediante la internacionalización de la mayoría de las variables que inciden en el proceso de transformación que cada país debe experimentar, hará posible el control de las variables y así minimizará los costos y las interrupciones que provoque el proceso al tiempo que garantice en mayor grado su dirección.

v) Alguna forma de entendimiento debe ser alcanzado con Europa Oriental, ya que la integración de Europa Occidental sin duda hace nacer esperanzas y temores, tanto políticos como económicos. Por lo tanto, no deben escatimarse los esfuerzos para evitar que el proceso de transformación $\mathrm{cum}$ integración europeo sea visto como desestabilizador en Europa Oriental. Al mismo tiempo, se debe estructurar nuevamente las relaciones con EE. UU. Subsiste, sin embargo, el peligroso sueño de una Alemania unida, es decir que si Alemania (Occidental) mira hacia el Este, se debilita toda la base de la Comunidad Europea ${ }^{64}$.

3.0. La crisis que ha golpeado a Europa más que a los demás

"Zysman y Cohen: "Double or Nothing", 1124; también R. Reich: "Beyond Free Trade" y A. Bressand: "Mastering the "World Economy", ambos en Foreign Affairs, 61, 4, primavera de 1983

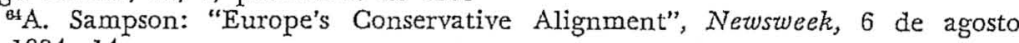
de 1984, 14. 
PD es la fractura de las frágiles economías de América Latina, que hacen del Sur el área más afectada.

Lo que se reconoce ahora como la peor crisis económica a contar de la independencia, ha paralizado el crecimiento de América Latina. (El PNB declinó en un 3,8\% durante 1983) y ha deprimido peligrosamente los niveles de vida; entre 1980 y 1983 el ingreso per cápita disminuyó en más de un $10 \%$, creando de este modo situaciones potencialmente explosivas en muchos países de la región. La pobreza ha aumentado como resultado tanto del creciente desenpleo como de la baja de recursos fiscales para programas sociales de mantención, y en algunos países la situación es aún más grave de lo que describen los promedios regionales. Esta crisis tiene, naturalmente, más de una causa, pero el grado de endeudamiento es visto en forma cada vez más generalizada como la más relevante, tanto así que en 1982 un semanario de gran influencia se sintió en la obligación de colocar el siguiente titulo a un extenso informe sobre esa región: "América Latina se sume en una depresión para pagar sus deudas" 65 , un tema que ha sido extensamente analizado desde entonces, tanto dentro como fuera de la región, por académicos así como por organizaciones gubernamentales e internacionales. Puede resultar entonces más fructífero explorar la influencia y las posibilidades reales a las que da lugar la crisis y otros acontecimientos recientes en la región fuera de la esfera económica y sobre la evolución tanto de las relaciones interlatinoamericanas como hacia el exterior.

3.1. La primera tendencia y la más visible es la de un lento pero seguro desplazamiento hacia sistemas políticos representativos, tendencia que es tanto más importante en vista de los crecientes sacrificios que los programas de estabilización que requiere la crisis están exigiendo por parte de amplios sectores de la población. En países donde el gobierno militar no aplica tendencias involutivas, éstas no han surgido como muchos esperaban, y aún las instituciones mexicanas están soportando el impacto de la crisis. Esto demuestra la estabilidad que ha sido lograda por los gobiernos latinoamericanos y la madurez alcanzada por sus poblaciones.

Un segundo hecho tiene relación con la aparente respuesta común que la Guerra de las Malvinas y el programa de la deuda han elicitado por parte de la organización política de América Latina. Si estos ejemplos constituyen verdaderamente una tendencia a Ia tanto-tiempo-soñada unidad continental, es demasiado pronto y arriesgado decirlo; pero son demasiado importantes para ser pasados por alto. Aún más, el proceso de integración de América Latina no puede ser desasociado de su relación con EE. UU., y es el estado de esta relación el que tiende a dar fundamento a la idea que

${ }^{\infty}$ The Economist, 25 de septiembre de 1982, 73. 
las condiciones para una acción coordinada por parte de América Latina, finalmente, se estarían dando: De hecho, el rol de Washington en la Guerra de las Malvinas fue en gran parte la expresión o el reflejo de un severo deterioro anterior de los lazos EE. UU.América Latina, y en ese Sistema Militar Inter-Americano que ha constituido la columna vertebral de esta relación a partir de $1938^{66}$. La fundación del SELA (Sistema Económico Latino-Americano) fue otra señal de este proceso de deterioro, como lo ha sido el Grupo Contadora $y$, últimamente, la reunión de Cartagena para coordinar una posición común con respecto al problema de la deuda. Todos éstos subrayan la posibilidad de crear un sistema de seguridad exclusivamente latinoamericano si el gobierno de EE. UU. continúa ignorando esta vasta región, excepto cuando la crisis financiera amenazó con estallar. El poco interés o la descuidada negligencia por parte de EE. UU. hacia el continente, constituye claramente una falta de visión' ${ }^{\prime 67}$, y muchos estudios norteamericanos recientes comparten el punto de vista que la influencia de EE. UU. en América Latina, aunque todavía es significativa, está declinando ostensiblemente. El sentido de unidad en América Latina está creciendo: las Malvinas sepultaron la Doctrina de Monroe y el rol de EE. UU. para garantizar la seguridad de la región. El problema de la deuda es la primera ocasión que tienen los países de América Latina para actuar en conjunto en este varío, como lo han probado algunos al ayudar a Argentina a pagar su deuda la primavera pasada.

En tercer lugar, a medida que los asuntos de seguridad en la relación EE.UU.-América Latina retroceden en el escenario y la dimensión económica adquiere mayor relevancia, Amér:ca Latina se torna cada vez más consciente de que sus intereses y aquellos de EE. UU. son, básicamente, bastante diversos. La Guerra del Atlántico Sur hizo explotar el mito del panamericanismo y la creciente atención que EE. UU. ahora le presta a la Cuenca del Pacífico hace que sus prioridades queden claramente establecidas. Además, la preocupación del gobierno de EE. UU. por los problemas de la deuda de América Latina se debe principalmente al peligro que crea para el sistema financiero internacional y para los bancos norteamericanos, ya que cada punto añadido a las tasas de interés de EE. UU. significa más de $\$ 1,5$ mil millones de ingresos externos adicionales que necesita América Latina para financiar el servicio de su deuda ${ }^{68}$.

\footnotetext{
Hur. Muno: "Beyond the Malvinas Crisis: Perspectives on Inter-American Relations", Latin American Research Review, xIx, I, 1984, I58-161.

${ }^{\circ} \mathrm{R}$. Roett: "Democracy and Debt in South America: A Continent's Dilemma", Foreign Affairs, 62, 3, 1984, 696.

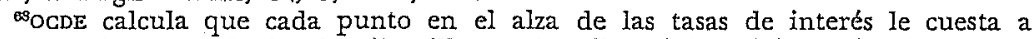
la OPEP alrededor de $\$ 1,9$ mil miliones; Brasil, México y Argentina enfrentan pagos adicionales de $\$ 1,35$ mil millones. ofCD: External Debt of Developing Countries, 1983 Survey, (Paris, OECD, 1984), 26. Ver tambien The Economist, 2 de junio de 1984, 76 .
} 
Cuarto, hay cada vez más competencia proveniente del Sudeste Asiático, lo que afecta la exportación de manufacturas de América Latina que, sobre una base per cápita, se mantiene bien por debajo de aquella de los países nombrados en primer término69. La participación de Japón en algunas de estas producciones contribuye a aumentar aún más el impulso exportador de Asia, mientras que las inversiones de EE. UU. en actividades equivalentes en América Latina tienden a estar dirigidas principalmente a la adquisición del mercado interno o regional. Europa observa atentamènte lo que sucede en el Sudeste Asiático; a partir de 1980 la CEE tiene un acuerdo de amplia cooperación con la ASEAN, en el que lá promoción del comercio representa un papel importante. Además, después de la experiencia de América Latina, 'Ia región del Pacífico provee una de las pocas oportunidades de préstamo seguro que les 'queda a los banqueros occidentales', que muy pronto podrán tener que competir con los bancos japoneses ${ }^{70}$. El financiamiento de los PRI del Asia parece, entonces, asegurado.

Quinto, la crisis está obligando a la mayoría de los países latinoamericanos a reevaluar las estrategias de desarrollo puestas en práctica. Hace ya algún tiempo que se llegó a la conclusión generalmente aceptada que la sustitución de las importaciones y la promoción de las exportaciones no constituyen políticas necesariamente opuestas, y la evidencia acumulada demuestra que son los mercados internos, más que los mercados externos, los que han hecho realidad la industrialización de los $\mathrm{PED}^{71}$. Actualmente, para muchos PED y ciertamente para varios en América Latina, la necesidad de exportar se torna más dramática en vista del creciente costo del servicio de la deuda, al tiempo que el persistente desempleo en los PD hace que las importaciones no sean bienvenidas. Cualquier reducción de la carga de la deuda aminoraría ciertamente la urgencia de los PED por exportar y volcaría el interés hacia el comercio regional y, en consecuencia, hacia la integración de la región. Si el

${ }^{6} D$. Morawetz: "Manufactured Exports, Labour Productivity and Employment in Latin America: A Hypothesis Based on the Clothing Industry in Colombia", en M. Syrquin y S. Tell (editores): Trade Stability, Technology and Equity in Latin America (N. York: New York Academic Press, 1982), 84, Table 6 .

${ }^{70}$ Newsweek: "Banking on Asia: West Meets East", 2 de julio de 1984, 35.

7D. Nayyar: "Transnational Corporation and Manufactured Export from Poor Countries", Economic Joumal, 83, 394, marzo de 1978. En el caso de Chile y Argentina "el proceso desustitutivo anuló también... los efectos potenciales favorables sobre el crecimiento del producto, atribuibles a la expansión de las exportaciones en los primeros años. Después de 1978, estas últimas tienen un impacto negativo de una magnitud similar al proceso desustitutivo directo. Anobos efectos combinados acentuaron la relación deficitaria del sector con el exterior". V. Moori-Koening y J. Weinstein: "Liberalismo Económico y Sector Industrial: Experiencias Recientes de Argentina y Chile", Economia de América Latina, 9, segundo semestre de 1982, 218. 
estancamiento y el proteccionismo se transformaran en algo crónico por parte de los $\mathrm{PD}$, la integración regional podría combinarse con una reorientación de las políticas de desarrollo que permitirían poner mayor énfasis en la sustitución de las importaciones, incluyendo la 'postergación de las importaciones y las inversiones en forma intensiva, utilizando bienes no comerciados (como la vivienda) ${ }^{72}$. Dado que las expectativas de que la recuperación de EE. uU. se extenderá hacia el sur, se torna cada vez menos convincente, los países latinoamericanos pueden llegar a la conclusión de que ellos tienen que encontrar una nueva locomotora entre ellos'T3.

Por último, existe evidencia reciente y confiable que aún en las economías que han sido más intensamente afectadas, como las de Mréxico y Brasil, el crecimiento ha vuelto a surgir; los excedentes comerciales visibles están aumentando tanto ahí como en Argentina ${ }^{74}$; y la estructura social no se ha aplastado bajo las tensiones de la deuda y los problemas relacionados. Expertos financieros han empezado a detectar signos que muestran los inicios del retorno de parte del capital de México, que había estado fugándose desde 198275. Latinoamérica está reordenando su economía en forma seria - austeridad sin recesión constituyó el tema de la Vigésima Sesión de la ecLA en Lima a principios de abril de 1984-y está luchando intensamente para poder cumplir con sus obligaciones, como lo demuestran los resultados positivos de los esfuerzos que ha efectuado. Así y todo, el futuro de la región estaría mejor asegurado si estos resultados no dependieran, en última instancia, de factores externos sobre los cuales América Latina tiene poco control: entre los factores más importantes se encuentra la tasa de interés que prevalece en el mercado internacional y que quiere decir, realmente, la tasa de interés de EE. uU., y la evolución de la recu-

${ }^{72} \mathrm{C}$. F. Diaz-Alejandro: "Some Economic Lessons of the Early 1980's", en J. N. Bhagwati y J. G. Reiggie (editores): Power, Passions and Purpone (Cambridge, Mass: The MIT Press, 1984), 197-98. También L. Taylor sostiene que, por lo menos en el caso de México, "Movement toward a more inward-oriented policy and more emphasis on income redistribution, may be inevitable over the next few years". "Mexico's Adjustment in the 1980s: Look Back Before Leaping Ahead, en R. E. Feinberg y V. Kallab (editores): Adjustment Crisis in the Third World (New Brunswick y Londres: Transaction Books, 1984), 157; y F. Parkinson: "Latin America, the Newly Industrializing Countries and the New International Economic Order", Journal of Latin American Studies, 16, Parte I, mayo de 1984, 132 .

${ }^{73}$ A. Sampson: "Democracy and Debt Bomb", Newsweek, 19 de marzo de $1984,4$.

${ }^{74}$ The Economist, 16 de junio de 1984, 54.

${ }^{\top 5} \mathrm{E} 1$ American Federal Reserve Board calcula que "over one-third of the $\$ 252$ billion increase of the major Latin American debtors beeween 1974 and 1982 went into buying assets overseas or was salted out in foreign bank accounts... The BIS estimates that some $\$ 50$ billion of capital flowed out of Latin America between 1978 and $1982 . .$. , but capital slowed to a trickle in 1983.', The Economist, 23 de junio de 1984, 75-6. 
peración de EE. UU. con el posible mejoramiento de Europa." Pero América Latina no puede permanecer por mucho tiempo como un neto exportador de capitalí. La carga de su deuda debe ser reducida de alguna manera para que América Latina pueda 'empezar a crecer' de nuevo ${ }^{77}$.

3.2. Dada la gravedad de la situación de América Latina y la constante amenaza que su endeudamiento plantea para el sistema financiero internacional, se han presentado varias propuestas para resolver el problema de la deuda, o al menos mitigar algunos de sus efectos más perniciosos ${ }^{78}$.

Basada en el análisis desarrollado aquí, se presenta, a grandes rasgos, la siguiente propuesta que se sostiene en cuatro considerandos que resultan evidentes casi por sí solos:

i) El pago de los intereses sobre préstamos comerciales se ha hecho casi insoportable para la mayoría de los PED, al mismo tiempo que el principal de la deuda siempre es renegociable;

ii) La actual crisis de la deuda ha sido causada por los pED en la misma medida que por los bancos de los $\mathrm{PD}^{7 \theta}$;

${ }^{70 E s t a ~ s i t u a c i o ́ n ~ c o n t i n u o ́ ~ e v o l u c i o n a n d o ~ e n ~} 1982$ y en 1983, cuando la región experimentó "a net outflow of... foreign exchange on the order of $\$ 27$ billion, which was made possible mainly by reducing imports $\rightarrow$ a factor which, in turn, was the main reason for the trade surplus recorded last year; InterAmerican Development Bank: External Debt and Economic Development in Latin America (Washington: Inter-American Development Bank, 1984), 5 y 6; Gráfico 1. De hecho, las exportaciones de Estados Unidos a América Latina bajó en un $40 \%$ entre 1981 y 1983 , baja que, según el Departamento de Comercio de Estados Unidos, significó para el país la pérdida de alrededor de 400.000 empleos.

${ }_{7 D}$ Discurso de E. Iglesias, Secretario Ejecutivo de la GEPAL, durante la $\mathrm{xx}$ Sesión de la cEPAL en Lima, impreso en Notas sobre la Economía y el Desarrollo Ĺatinoamericano, 393-394, mayo de 1984, 4.

${ }^{78}$ P. P. Kuczynski: "Latin American Debt", Foreign Affairs, 61, 2, invierno de 1982/83, 361.64; y "Latin America Debt: Act Two"; Foreign Affairs, 61; 1; otoño de 1983, 33-38; M. Zombanakis: "A Way to avoid a Crash", The Economist, 30 de abril de 1983; The Economist, 19 de febrero de 1983, 79; 2 de abril de 1983, 13; y 12 de mayo de 1984, 24; P. Kenen: "A Bailout Plan for the Banks", New York Times, 6 de marzo de 1983; N. Nancy: "Banks Must Acquire Equity in Debtor Countries", Wall Street Journal, 30 de septiembre de 1983; L. Silk en la "Economic Scene", de The Herald Tribune, 5-6 de mayo de 1984; H. Lever: "The Debt Won't be Paid", The New York Review, xxxi, 11, 28 de junio de 1984.

igu"Victims of a scam, debtors are treated as culprits", explota G. Maechling Jr. de la Carnegie Institute for International Peace, quien prosigue: "For this appalling state of affairs the major "money center" banks and economic advisers are largely responsible. In the $1970 \mathrm{~s}$, repeating the pattern of the $1920 \mathrm{~s}$, the bankers threw fiscal conservatism to the winds and engaged in a orgy of competitive lending. Loans were pressed on nations teetering on the brink of insolvency and at the mercy of world commodity prices. Academic quacks in the garb of 'development economist', propounded the fatuos doctrine that debt can be pyramided indefinitely". The Herald Tribune, $1^{9}$ de agosto de 1984. En 
iii) Los gobiernos de los países acreedores no pueden permanecer sin hacer nada y deben meterse... y manejar el pago de los intereses en forma política, no tomarlo como un problema económico-técnico ${ }^{80}$;

iv) La solución del problema de la deuda debe estar relacionada con el desarrollo de los PEDS1 y las políticas de ajuste de los PD.

Por lo tanto, como la relación entre prestamistas y prestatarios ha generado un grado inusual de interdependenciass, los bancos que prestan tendrán que aceptar recibir sólo dos tercios del interés vencido, la mitad del cual será pagado por el país deudor y la otra mitad por el gobierno acreedor. Tanto el país deudor como el gobierno acreedor formarán un fondo especial al que aportarán el equivalente de lo que le paguen a los báncos. Específicamente:

i) EI país deudor paga dos tercios del interés vencido, un tercio a los bancos en moneda extranjera y otro tercio a este fondo especial para financiar a) la inversión productiva necesaria para hacer revivir su desarrollo económico; o, en última instancia, "b) la amortización del principàl de la deuda.

ii) EI gobierno del PD aporta un tercio del interés vencido en forma directa a sus bancos y otro tercio a su fondo especial para financiar sus políticas de ajuste;

iii) Ambos fondos especiales quedarán bajo el completo control de sus respectivos gobiernos, pero sus actividades deberán ser coordinadas para evitar futuros desequilibrios como los que causaron ahora el problema de la deuda.

Esta propuesta se caracteriza porque tiene las siguientes ventajas:

i) No interfiere con la determinación de los niveles de las tasas de interés por parte del mercado y no necesita que se repudien previas obligaciones. Por lo tanto,

ii). capital fresco puede fluir hacia los PED, que pueden hacer una óptima utilización del desahogo que les ofrece esta propuesta y del financiamiento disponible mediante el fondo especial;

iii) puede haber un acuerdo bilateral entre un PED y un PD y

todo caso, a la altura del mes de mayo, "investors finally gave up believing the big American banks could avoid losses on their lonas to Latin America"; The Economist, 2 de junio de 1984, 75.

${ }^{80}$ H. Kissinger: "Solving the Debt Crisis: What's Needed is States-manship", The Herald Tribune, 25 de junio de 1984.

${ }^{81} \mathrm{Se}$. puede demostrar que "high indebtedness is a by-product of interest rates higher than the gross return on capital employed"; en otras palabras, cuando los intereses aumentan en mayor proporción que la utilidad de la inversión "in. debtedness becomes a self-feeding process". P. Manes: "International Indebtedness, Interest Rates and Inflation", Banca Nazionale del Lavoro Quarterly Review, 140, marzo de 1982, 109 y 113.

s2Kuczynski: "Latin American Debt: Act Two", 27. 
los bancos de este último; otros PD Y PED pueden adoptar el esquema y unírseles; esto implica la coordinación, si no la integración, entre los dos grupos;

iv) no requiere de la creación de un organismo internacional y ni siquiera tiene que involucrarse el FMr;

v) genera presión para que los PD encuentren maneras de detener el escalamiento de las tasas de interés; $y$, por último,

vi) reparte los sacrificios necesarios en forma equitativa.

La principal desventaja de esta propuesta es que necesita que exista la voluntad política para empezar a implementarla, desventaja que es común a todas las propuestas presentadas hasta ahora y de la cual poco se puede decir en este contexto.

Como acreedor de un $45 \%$ de la deuda comercial de América Latina ${ }^{83}$, es decir dos tercios del total de más de $\$ 300$ mil millones, es a EE. UU. a quien claramente le corresponde la iniciativa, pero la GEE, a quien le corresponde una porción no mucho menor, podría tomarla fácilmente si $\mathrm{EE}$. UU. no muestra poseer la calidad de estadista necesaria en las circunstancias y tan solicitada por Kissinger. Con los pagos de los intereses de América Latina, actualmente calculados en más de $\$ 40$ mil millones al año, los bancos comerciales pueden esperar obtener cerca de $\$ 30$ mil millones neto, monto del cual los bancos europeos recibirán un poco menos de la mitad. Un acuerdo entre la CEE y América Latina con el fin de poner en práctica esta propuesta le ahorraría \$5 mil millones a Latinoamérica y obligaría a la CEE a utilizar una cantidad equivalente para ajustarse al medio ambiente internacional que está cambiando. Una parte de estas sumas se podría utilizar para financiar la promoción y coordinación de comercio de mutuo beneficio, así como en servicios y flujos de inversión entre ambos continentes.

El fondo especial de los PD también se podría utilizar para financiar la creación de una especie de servicio de extensión de fábrica propuesto por Zysman y Gohen, es decir, una infraestructura compleja para dar apoyo tecnológico, financiero y de mercado a pequeñas y medianas industrias para ayudarles a aumentar la productividad y para introducir alta tecnología a la producción de bienes tradicionales ${ }^{84}$. A diferencia del caso de los recursos concebidos en el plan Albert y Ball, los recursos de los pD que se necesitan para poner en práctica esta propuesta deberían obtenerse in-

\footnotetext{
${ }^{3}$ Ibid, 27. A fines de 1980, los préstamos internacionales de la Banca Americana alcanzaron los $\$ 67$ mil millones: México $\$ 26$ mil millones, Brasil $\$ 21$ mil millones, Venezuela $\$ 11$ mil millones $\%$ Argentina, $\$ 9$ mil millones. Los bancos americanos más expuestos fueron Citicorp (\$ 10,3 mil millones), el Bank of America y J. P. Morgan (\$ 7,4 mil millones cada uno); The Economist, ? de junio de I984, 75 .

${ }^{8 Z}$ Zysman y Cohen: "Double or Nothing", 1137-38.
} 
ternamente a través de impuestos adicionales y reducciones presupuestarias, para poder redistribuir el costo de la operación de salvataje de acuerdo con la responsabilidad que le cabe al sistema bancario de cada país en el origen de la deuda. La utilización de los recursos en ambos esquemas debe ser cuidadosamente coordinada, de tal manera que el ajuste europeo facilite el desarrollo de América Latina en vez de generar los desequilibrios y las tensiones que la evolución de los po ha tendido a proyectar en el resto del mundo. El servicio de la deuda no debe detener más el desarrollo económico y poner en peligro la estructura social y política de los países en desarrollo más promisorios. Más aún, los pD no parecen tener la capacidad necesaria para lidiar con las exigencias y las cargas que les corresponderían por ser naciones más rentables, según el grado de responsabilidad ${ }^{85}$.

El manejo actual de la crisis de la deuda constituye ya un caso de coordinación internacional. Para transformarlo en un plan efectivo necesitamos perspectivas a largo plazo, la participación explícita de los gobiernos involucrados, y sacrificios por parte de los países acreedores tanto como los deudores; en otras palabras, una calidad de estadista con un alto grado de valentía.

4.0. Históricamente, las relaciones entre Europa y América Latina han sido bastante estrechas, aun cuando en la actualidad se hayan visto hasta cierto punto reducidas por la reciente hegemonía norteamericana ${ }^{86}$. A partir de la Segunda Guerra Mundial, sin embargo, Europa no le ha prestado atención a este importante subsistema de Ia economla mundialst y cada vez que América Latina ha acudido a Europa en busca de ayuda, para no nombrar siquiera las veces que ha tratado de recurrir a Europa antes que a EE. UU., sus expectativas se han visto destrozadas; peor aún, ha visto a Europa tomar partido junto a EE. UU.

Dos puntos de vista han surgido entonces en torno a las relaciones Europa-América Latina:

i) América Latina resiente, y critica violentamente, las políticas de Ia CEE más que aquella de cualquier país europeo individualmente;

ii) Europa, y ciertamente la CEE, demuestra una 'negligencia benigna' hacia AL, motivada oficialmente por la creencia de pro-

"Lever: "The Debt Won't be Paid", 3.

${ }^{80}$ S. Sideri: "Crisi Mondiale, Crisi dei Modelli di Sviluppo Latino-Americani e Relazioni Economiche della Comunita Europea con l'America Latina", Giornale degli, Economisti e Annali di Economia, 15, septiembre-octubre de 1983, 601-16.

${ }^{87 W}$. Grabendorff: "Latin America and Western Europe: Towards a New Internattional Subsystem?", en J. Pearce (ed.): The European Challenge: Europe's New Role in Latin America (Londres: Latin American Bureau, 1982). 
yectos concretos en común por parte de los países latinoamericanos. Afortunadamente, estas dos posiciones se ven suavizadas en general por sentimientos de amistad y la voluntad de cooperación que inspira a ciertos países y a ciertos grupos europeos.

A fin de cuentas, sin embargo, la cooperación económica entre Ios dos no ha sido particularmente estrecha a partir de '1945. Han predominado intereses económicos a corto plazo, aun cuando las relaciones económicas, especialmente en lo que se refiere a inversiones, se han desarrollado siempre sobre la base del intercambio y el contacto bilateral. Los principales obstáculos a la cooperación con América Latina por parte de Europa pueden apreciarse en su Política Agrícola Común, en los diversos Tratados Lomé, y en la crisis económica. Hasta ahora, la $\mathrm{CEE}$ ha sido más importante para América Latina que viceversa. Mientras la CEE constituye el segundo mercado más importante para América Latina, la capacidad de ésta para penetrar la CEE a partir de 1974 ha demostrado ser inferior que la demostrada en otras áreas. De hecho, $60 \%$ de sus exportàciones a Ia GEE son agrícolas, lo que transforma a América Latina en el mayor proveedor de alimentos, abasteciendo un $10 \%$ de las importaciones de productos comestibles extra-cEE. Aún más, América Latina abastece un $11 \%$ de las importaciones de mineral de la CEE, tales como el tungsteno, el cobre, el hierro, el mineral de hierro, el manganeso y el zinc. Durante la década pașada ha sido el mayor proveedor de cinco materias primas que son esenciales para la industria de la CEE.

Latinoamérica también ha sido un buen mercado para los bienes manufacturados europeos, que constituyen un $88 \%$ de las exportaciones de la CEE, con un valor promedio anual de $\$ 8$ mil millones, Brasil y Argentina son de Iejos los socios más importantes de la CEE en América Latina; en 1978, un 30\% de las exportaciones brasileñas y un $34 \%$ de las argentinas se hicieron a la CEE, mientras que un $19 \%$ y un $31 \%$ de sus respectivas importaciones provinieron de la $\mathrm{CEE}^{88}$.

Es importante destacar que mientras la GEe ha demostrado poco interés en las relaciones comerciales con América Latina, la inversión privada directa y los flujos financieros europeos hacia la región han aumentado considerablemente. En 1976, América Latina absorbió un $15 \%$ del total de la inversión privada directa por parte de Europa, principalmente hacia las manufacturas deștinadas a mercados internos o regionales, para así sustituir las exportaciones europeas tradicionales. Las inversiones de Europa en "América La. tina durante el mismo año representaron un $26 \%$ de las inversiones extranjeras en el área (de $23 \%$ en 1967), mientras que las inver-

\footnotetext{
sqEurostat: Analysis of Trade Between the European Community and the Latin American Countries, 1965 -1980 (Bruselas: EEc, 1981).
} 
siones de EE. UU, disminuyeron de $561 \%$ a $51 \%$ en el mismo período 1967-76. La inversión privada europea en Brasil, por ejemplo, sobrepasó la de EE. UU. Esta expansión de la inversión europea no sólo es bienvenida sino que se considera que 'algunas compañías europeas han demostrado ser más flexibles que las de norteamérica en diversos casos, en lo que se refiere a su modo de operar en países de América Latina' 89 .

4.1. Se justificaría para la CEE una cooperación más estrecha con América Latina por las siguientes razones:

i) Razones económicas: la necesidad de: a) mercados para sus propios productos manufacturados, especialmente aquellos con tecnología más sofisticada, para bienes de capital y para servicios; b) la importación de bienes de consumo a precios convenientes de manera de reducir la inflación en el seno de la GEE y controlar la espiral de los salarios; c) la importación de minerales y energía, aún si fuera sólo con el fín de contrapesar la creciente dependencia de Africa y del Medio Oriente. América Latina, con un mércado de cerca de 400 millones de personas cuyo ingreso promedia alrededor de los $\$ 1.300$, con un $70 \%$ de los adultos alfabetizados cuya expectativa de vida promedia los 63 años, y un sector manufacturero que contribuye con no menos de un $30 \%$ del PIB, constituye claramente el mercado comercial más grande para la CEE en el Tercer Mundo. La complementaridad con la CEE es potencialmente muy alta, como lo demuestra la fuerte demanda de bienes de capital europeos por parte de Argentina y Brasil y por la expansión comercial y financiera de Alemania en el continente ${ }^{90}$. Para permitir que esta complementar:dad surja, es necesario abandonar las actuales tendencias proteccionistas o utilizarlas selectivamente de tal manera de ahorrar exportaciones de América Latina y así dar comienzo a una reestructuración industrial seria, acordada con la Comunidad, junto con una coordinación más estrècha entre política industrial, inversión europea en América Latina y ayuda a la región. La propuesta para el manejo de la deuda presentada en el item 3.2. se prestaría de un modo excelente para estos propósitos. En resumen, esta apertura hacia América Latina ayudaría a Europa a escapar de la actual crisis y podría constituir la base sobre la cual formular y ejecutar una política económica realista, en conjunto.

${ }^{8} N$. González: "Relaciones Económicas de América Latina con Ia Comunidad Económica Europea", (mimeo; Santiago de Chile: GEPAL, 20-21 de mayo de 1982), 9.

${ }^{\circ} \mathrm{Y}$. Berthelot y J. de Bandt: Impact des Relations avec le Tiers Monde sur l'Economie Française (Paris: La Documentation Française, 1982) para Francia; y Hamilton y Krenin: "The Structural Pattern", 274 en general concluyen que los psBd más industrializados constituyen más bien potenciales clientes para Europa que rivales. 
ii) Razones polfticas: la entrada de España a la GEE intensificará la necesidad de adoptar una política hacia América Latina con la que la CEE estaría interesada en fortalecer las tendencias latinoamericanas hacia la democracia, como lo han demostrado las acciones emprendidas por las internacionales Social Demócrata y Demócrata Cristiana. Esta política debería ayudar a evitar posibles resurgimientos autoritarios y reducir las tensiones Norte-Sur, ya que América Latina constituye la parte más desarrollada y agresiva del Tercer Mundo. Por último, la política de extender una mano por parte de la CEE daría apoyo a la determinación latinoamericana de reducir su dependencia de EE. uv. y así diversificar sus relaciones económicas y políticas. Efectivamente, las dos áreas tienen un interés común en oponerse a los planes de las superpotencias.

iii) Razones polf́ticas y económicas: relaciones diagonales con América Latina ayudarían a la CEE a reforzar y evitar la alternativa que existe de la dominación americano-japonesa; contrapesar el creciente desplazamiento del eje económico hacia el Pacífico; $y$, por último, participar más activamente en la reorganización de la economía mundial impuesta por la actual crisis, una crisis que, hasta el momento, Europa ha aceptado pasivamente.

La creación y la puesta en práctica de una política integrada de la CEE hacia América Latina, con la discriminación y la inteligencia necesarias para captar su realidad compleja y heterogénea, constituirían una ocasión histórica para que la CEE desarrolle un enfoque global en sus relaciones internacionales y de este modo mantener, sin la protección de EE. UU., el sitial que ha conquistado dentro de la economía mundial.

Ambas regiones han llegado a una encrucijada y se ven enfrentadas a un gran desafío: Europa puede ser ayudada por, y a su vez puede ayudar a, América Latina, ya que si la esperanza de América Latina de independizarse hoy día pasa ... a través de Europa ${ }^{91}$, el futuro económico de Europa también pasa a través de América Latina.

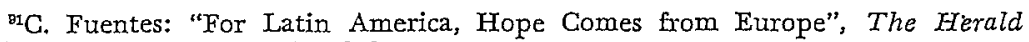
Tribune, 13 de febrero de 1983. 